\title{
Compras públicas: um estudo das micro e pequenas empresas de um município de médio porte localizado no sul de Minas Gerais
}

Luis Paulo Nascimento ${ }^{1}$

Daniela Andrade ${ }^{1}$

Vinícius Gonçalves ${ }^{1}$

Andressa Aparecida Santana Furtini ${ }^{1}$

${ }^{1}$ Universidade Federal de Lavras 


\section{COMPRAS PÚBLICAS: UM ESTUDO DAS MICRO E PEQUENAS EMPRESAS DE UM MUNICÍPIO DE MÉDIO PORTE LOCALIZADO NO SUL DE MINAS GERAIS}

Resumo: O processo de licitações públicas é uma ferramenta para o incentivo do desenvolvimento local e regional, já que segundo o Serviço Brasileiro de Apoio às Micro e Pequenas Empresas (SEBRAE, 2014), as compras públicas movimentam anualmente, cerca de 500 bilhões de reais nas esferas Federal, Estadual e Municipal. Assim, o objetivo deste estudo foi analisar a participação das MPE's de um município de médio porte localizado no Sul de Minas Gerais em processos licitatórios. Foram analisados dados mensuráveis obtidos por meio da aplicação de questionário semiaberto com 56 representantes de MPE's desse município. Os resultados indicaram que há uma aplicação do tratamento favorecido e simplificado destinado às MPE's, além de uma boa interpretação por parte dos possíveis participantes de que o ente público pode influenciar no desenvolvimento local, como também é percebido que o poder público não tem efetuado a divulgação destes processos de forma ampla.

Palavras-chave: Licitação Pública. Microempresa. Empresa de Pequeno Porte. Desenvolvimento local.

\section{Introdução}

A Constituição Federal Brasileira de 1988, em seu artigo 37, inciso XXI, estabelece que as obras, serviços, compras e alienações deverão ser contratados por meio de processo de licitação pública, sendo assegurada a igualdade de condições a todos os concorrentes e cláusulas que estabeleçam obrigações de pagamento, exigindo-se para participação apenas qualificação técnica e econômica indispensável para o cumprimento do objeto a ser contratado (BRASIL, 1988).

A Lei 8.666/93 foi instituída com o objetivo de regulamentar a referida norma constitucional, instituindo normas gerais sobre licitações e contratos administrativo relativos a obras, serviços, inclusive de publicidade, compras, alienações e locações.

Visando seguir o princípio da isonomia, que segundo Mello (2011, p. 7) é "o princípio da igualdade que interdita tratamento uniforme às pessoas" e, por isso a democracia deve ser o ponto crucial para que haja a igualdade de direitos e deveres de maneira e, por conseguinte, a participação dos pequenos negócios nos processos licitatórios de compras públicas.

Dessa forma, foi criada a Lei Complementar ${ }^{\circ} 123$ de 14 de dezembro de 2006 com o intuito de tornar aplicável o princípio da igualdade por meio de um tratamento diferenciado às micro e pequenas empresas nos processos de compras governamentais, possibilitando a concorrência com as grandes empresas e fomentando sua inserção no mercado, promovendo o desenvolvimento econômico, a eficiência das políticas públicas e incentivando a inovação tecnológica.

De acordo com Serviço Brasileiro de Apoio às Micro e Pequenas Empresas (SEBRAE, 2014a), das 9 milhões de empresas formais existentes no país, 99\% são MPE's,
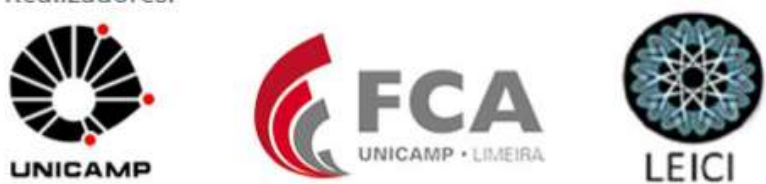
sendo estas responsáveis por cerca de $52 \%$ dos empregos formais, fato este que ratifica a inarredável importância de tais empreendimentos para a economia.

As compras públicas movimentam cerca de 500 bilhões de reais por ano na esfera Federal, Estadual e Municipal, incluindo o Distrito Federal. Portanto, a contratação de MPE's por parte da Administração Pública pode ser uma eficiente estratégia para fomentar o desenvolvimento econômico (SEBRAE 2014c).

$\mathrm{O}$ ato da participação em compras públicas gera importantes resultados para grandes empresas, pois estas possuem estrutura e capacidade técnica capaz de atender certas demandas. Por outro lado, tem se certa desconfiança e imaturidade por grande parte dos gestores de MPE's que desconhecem as mais variadas formas de fornecer produtos e serviços aos entes públicos, além, é claro, da dificuldade de atender a grande quantidade de normas e diretrizes a serem seguidas, que muitas das vezes são conhecidas ou explicitadas aos microempresários, eximindo-os automaticamente da disputa de ofertas (SEBRAE, 2014a).

Mesmo tendo a Lei Complementar $n^{\circ} 123 / 2006$ e posteriormente sua atualização elaborada pela Lei Complementar $n^{\circ} 147 / 2014$ (BRASIL, 2014), existem muitos outros problemas que são enfrentados pelas MPE's, no que diz respeito as informações para o procedimento competitivo, ou seja, falta acesso à legislação ou falta de capacitação do envolvidos. Há também a inexistência de um planejamento estratégico por parte das MPE's para poderem participar das compras públicas. Segundo Matos e Arroio (2011), dificuldades recorrentes nas MPE's podem estar ligadas também aos recursos humanos escassos e às capacitações técnicas, tecnológicas e gerenciais inexistentes, bem como ao seu menor poderio de barganha perante fornecedores, clientes, bancos e agências de desenvolvimento.

Diante desse contexto, a presente pesquisa buscará responder a seguinte questão: Quais as vantagens e as dificuldades enfrentadas pelos micro e pequenas empresas de um município de médio porte localizado no Sul de Minas Gerais no que diz respeito à participação nos processos de compras públicas?

Nesse sentido, o objetivo geral deste estudo foi analisar a participação das MPE's de um município de médio porte localizado no Sul de Minas Gerais nos processos licitatórios realizados na esferas municipais, estaduais e federais. Buscou-se verificar as opiniões dos representantes das MPE's sobre os processos de compras públicas; diagnosticar soluções para gargalos identificados, a partir do ponto de vista dos representantes e verificar o conhecimento dos empresários entrevistados sobre os benefícios da LC 123/06 (BRASIL, 2006) e da LC 147/14 (BRASIL, 2014).

A importância desta pesquisa reside no fato de que a participação de micro e pequenas empresas em procedimentos de compras públicas pode trazer reflexos no desenvolvimento local, impulsionando o crescimento da economia. Identificar e compreender as questões que envolvem ou limitam a participação das MPE's em licitações possibilita que o gestor público atue de forma a concretizar tal participação, agindo diretamente sobre os problemas verificados.

O trabalho encontra-se estruturado em cinco partes, iniciando pela introdução. Já o referencial teórico está dividido em três partes: a primeira apresenta a conceituação das MPE's; a segunda denota os princípios e prerrogativas dos processos licitatórios e a terceira abrange o processo de desenvolvimento local, a partir das MPE's.

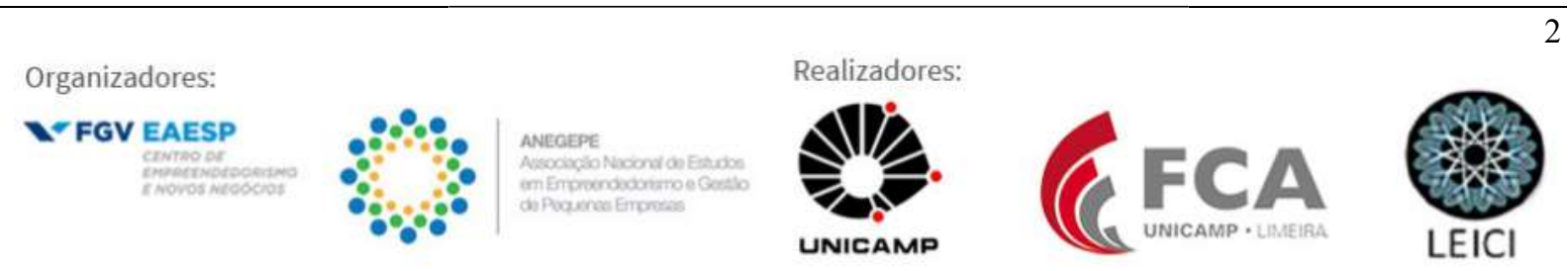


A metodologia utilizada para a elaboração do estudo é de origem quantitativa, com foco na descrição, pois tem a preocupação em identificar e estudar fatos já conhecidos que determinam ou que contribuem para a ocorrência dos fenômenos estudados.

Nos resultados e discussões são analisadas as devolutivas dos representantes das empresas pesquisadas, a partir da identificação dos benefícios e das dificuldades encontradas por estes, bem como o levantamento da utilização ou não dos benefícios concedidos pela legislação, por parte das empresas licitantes.

Por derradeiro, são elencadas as conclusões obtidas por intermédio dos resultados, propondo-se ações que possam incentivar, efetivar e disseminar a participação das MPE's nas licitações, bem como a criação de parcerias entre municípios e as entidades de classe existentes, além da inserção dos entes públicas no ambiente destas empresas.

\section{Referencial Teórico}

\subsection{Conceituando as MPE's}

No Brasil ainda é recente a noção sobre a importância das MPE's como propulsoras para o desenvolvimento local. O Estado tem possibilidades constitucionais e legais de utilizar seu poder de compra com o objetivo de promover o desenvolvimento das MPE's, além de aumentar o grau de apropriação interna das inovações e fomentar o crescimento e desenvolvimento local no âmbito econômico e social (MAZZUCATO, 2014).

A Constituição Federal de 1988 trouxe a possibilidade de impor tratamento jurídico favorecido, diferenciado e simplificado para as empresas de pequeno porte, e a Lei Complementar $n^{\circ} 123 / 2006$ concretizou tal benefício mediante a elaboração de regras objetivas para tais preceitos constitucionais (SEBRAE, 2014a).

Segundo Lei Complementar 123/2006, entende-se como microempresa (ME) a sociedade empresária, a sociedade simples e o empresário, devidamente registrados, que recebam, em cada ano-calendário, receita bruta superior a $\mathrm{R} \$ 60.000,00$ (sessenta mil reais) e igual ou inferior a $\mathrm{R} \$ 360.000,00$ (trezentos e sessenta mil reais) (BRASIL, 2006).

De acordo com a mesma norma, entende-se como empresa de pequeno porte (EPP) a sociedade empresária, a sociedade simples e o empresário, devidamente registrados, que recebam, em cada ano-calendário, receita bruta superior a $\mathrm{R} \$ 360.000,00$ (trezentos e sessenta mil reais) e igual ou inferior a $\mathrm{R} \$ 4.800 .000,00$ (quatro milhões e oitocentos mil reais) (BRASIL, 2006).

Por derradeiro, entende-se como microempreendedor individual (MEI) a sociedade simples e o empresário, devidamente registrados, que recebam, em cada ano-calendário, receita bruta inferior a $\mathrm{R} \$ 60.000,00$ (sessenta mil reais) (BRASIL, 2006).

Em conformidade com o art. 72 da Lei Complementar $n^{\circ}$ 123/2006 (BRASIL, 2006), a forma jurídica das MPE's devem obrigatoriamente, estar inseridas na redação do nome empresarial, neste caso, no Cadastro Nacional de Pessoa Jurídica - CNPJ. Logo, a identificação dos empresários ou sociedades enquadradas como MPE's, poderá ser realizada mediante solicitação à Junta Comercial do cadastro das "declarações de enquadramento" arquivadas naquele estabelecimento.

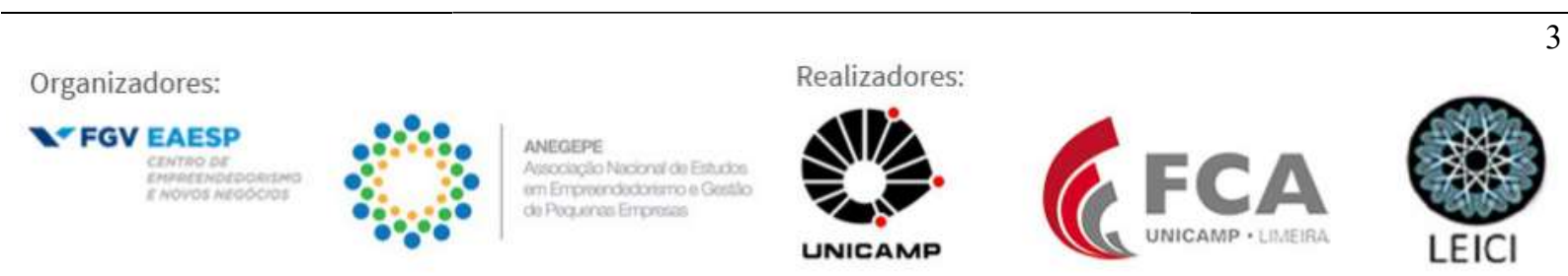


A Lei Complementar $n^{\circ} 123 / 2006$ criou, ainda, o regime especial unificado de arrecadação de tributos e contribuições devidos pelas microempresas e empresas de pequeno porte - SIMPLES NACIONAL, que implica o recolhimento mensal dos impostos federais, estaduais e municipais em um único documento (BRASIL, 2006), abrindo espaço para que as MPE's participem competitivamente dos processos de compras públicas.

Segundo Cabral, Reis e Sampaio (2015, p. 483) "as licitações realizadas pelos órgãos e entidades da administração direta e indireta federal, com a intenção de viabilizar maior concorrência e apoio às MPE, podem ter participação exclusiva dessas empresas".

O artigo 48 da Lei Complementar 123/2006 prevê a realização de licitações com a participação exclusiva de MPE's para contratações cujo valor seja de até R\$ $80.000,00$ (oitenta mil reais), a possibilidade de exigir dos licitantes vencedores a subcontratação de microempresa ou empresa de pequeno porte no caso de obras e serviços e o estabelecimento de cota de até $25 \%$ do objeto para contratação de microempresas e empresas de pequeno porte, quando o objeto da licitação for aquisição de bens de natureza divisível (BRASIL, 2014).

Destarte, torna-se inarredável, para consecução desse trabalho, um estudo sobre o processo de compras públicas. No próximo tópico serão apresentadas questões relevantes sobre licitações previstas na Lei $n^{\circ} 8.666 / 1993$ e na Lei ${ }^{\circ}$ 10.520/2002.

\subsection{Compras Públicas}

A licitação é um procedimento delineado por princípios do Direito Administrativo, direcionado à escolha de um possível contratante que será submetido a determinadas fases indispensáveis tanto pela Administração Pública quanto pelos licitantes participantes do certame em questão (DI PIETRO, 2008).

A Lei que regulamenta essas contratações é a Lei $N^{\circ} 8666$ de 21 de junho de 1993, e, de acordo com o seu artigo $3^{\circ}$, o objetivo desse processo é garantir a verificação do princípio constitucional da isonomia, a seletividade da proposta considerada mais vantajosa para o ente público e a promoção do desenvolvimento nacional pautado na ideia da sustentabilidade, sendo processado e julgado perfeitamente e em conformidade com os princípios básicos da legalidade, da impessoalidade, da moralidade, da igualdade, da publicidade, da probidade administrativa, da vinculação ao instrumento convocatório, do julgamento objetivo e tudo que aquilo que se encontra correlato (BRASIL, 1993).

Assim, tem-se na lei as diversas modalidades. A modalidade Concorrência é decorrente da Lei 8.666/1993, art. 22, $\S 1^{\circ}$ sendo a modalidade de licitação que pode ser realizada entre qualquer interessado, sendo que em sua fase inicial de habilitação, esteja comprovado que possua os requisitos mínimos de qualificação exigidos para a execução do objeto no edital (BRASIL, 1993).

A modalidade tomada de preços é regida pela Lei 8.666/1993 (art. 22, $\S 2^{\circ}$ ) refere-se ao modelo de licitação entre interessados já cadastrados ou que atendam todas as condições exigidas no ato do cadastramento até o terceiro dia anterior à data do recebimento das propostas formuladas, sendo visto a necessária qualificação dos entes participantes (BRASIL, 1993).

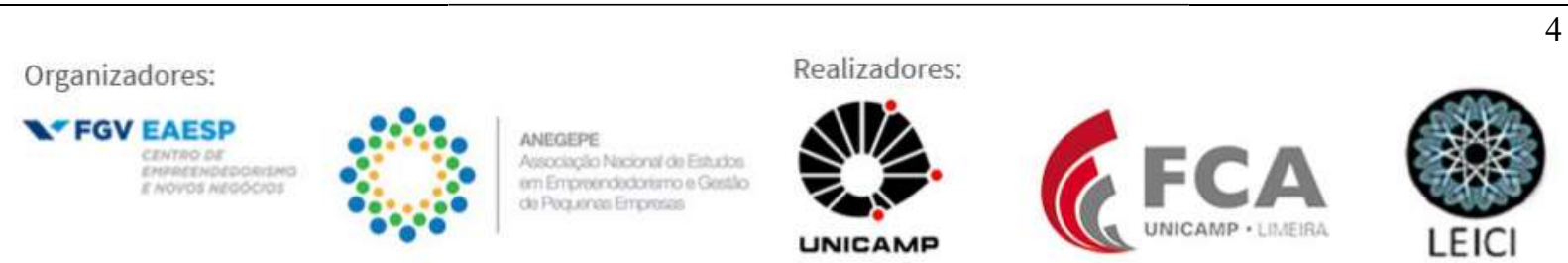


A modalidade Convite é a modalidade entre interessados do ramo, cadastrados anteriormente ou não, escolhidos e convidados em número mínimo de 3 (três) pela unidade administrativa, no qual serão definidos, em local previamente avisado e comungado entre as partes, cópia do instrumento convocatório que se promoverá aos demais cadastrados na correspondente especialidade que manifestarem seu interesse com antecedência de até 24 (vinte e quatro) horas da apresentação das propostas (BRASIL, 1993).

A modalidade Concurso é destinada quando a Administração Pública tem interesse em selecionar trabalho técnico, científico, projeto arquitetônico ou artístico, ou seja, para trabalhos que exijam determinadas capacidades personalíssimas, portanto não existe contratação, somente premiação ou remuneração (BRASIL, 1993).

O leilão também é considerado como uma modalidade de licitação para venda de bens móveis inservíveis para a Administração Pública ou de produtos legalmente apreendidos ou penhorados, ou para a alienação de bens imóveis prevista no art. 19, a quem oferecer o maior lance, igual ou superior ao valor da avaliação (Redação dada pela Lei $n^{\circ} .8 .883$, de 8.694) (BRASIL, 1993).

E a última modalidade de licitação é o pregão, que foi institucionalizado pelo Governo Federal por meio da Lei Complementar $n^{\circ} 10.520$, de 17 de julho de 2002, sendo do tipo menor preço, utilizado exclusivamente para aquisição de bens e prestação de serviços comuns, sob qualquer valor estimado que seja da contratação, bem como a disputa é feita por meio de propostas e lances sucessivos em sessão pública, sendo excluídas desta modalidade as contratações de obras e serviços de engenharia além de locações imobiliárias e alienações em geral, sendo que serão regidas pela legislação geral de Licitação (BRASIL, 1993). Como importante meio de inovação e desburocratização, o pregão é representado pela inversão das fases de habilitação e análise das propostas, em que apenas será analisada a documentação do participante que tenha apresentado a melhor proposta (BRASIL, 1993).

Nas licitações convencionais, como a concorrência, a tomada de preços, o convite, o concurso e o leilão, o procedimento é conduzido por uma comissão de licitação designada por decreto. Na modalidade pregão, é de responsabilidade do pregoeiro e sua equipe de apoio realizar os atos administrativos durante o certame (DI PIETRO, 2008).

Diante de todo o procedimento licitatório, é de responsabilidade do pregoeiro e sua equipe colocar em prática as normas vigentes da legislação, entre elas a do tratamento diferenciado e favorecido às MPE's, de acordo com a LC 123/06 (BRASIL, 2006) e suas alterações contempladas na LC 147/ 14 (BRASIL, 2014).

\subsection{Desenvolvimento local a partir das MPE's}

As MPE's são uma alternativa de ocupação e geração de renda para a fatia da população que tem interesse em desenvolver seu próprio negócio, sendo muitas vezes chamados de empreendedores, pois geraram empregos formais e informais para uma grande parte da força de trabalho não empregada em grandes empresas ou no funcionalismo público (IBGE, 2017).

Esses empreendedores, segundo Drucker (1992) são os indivíduos que inovam no sentido de empreender, pois tal ação contempla a utilização de recursos para a geração de novas riquezas e oportunidades.

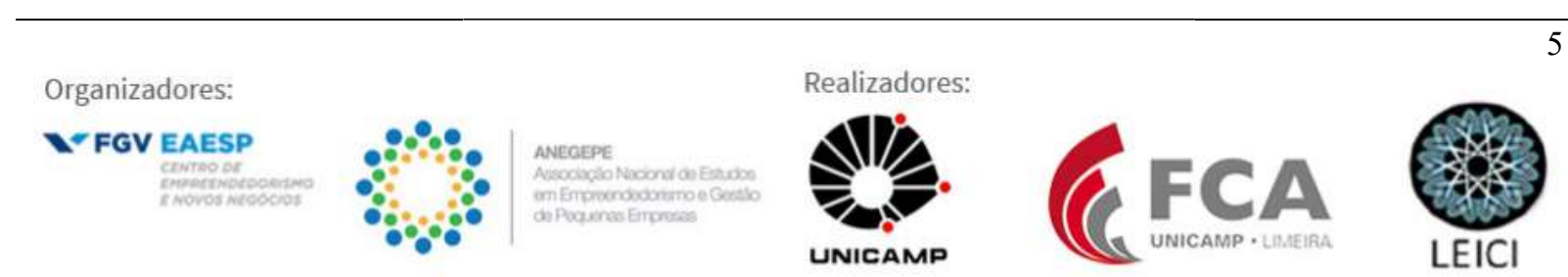


Souza (1995) complementa que além da relevância socioeconômica, as MPE's oferecem contribuições em diversos campos, com destaque para o estimulo à liberdade de iniciativa e capacidade empreendedora; criação de uma relação harmoniosa entre o capital e o trabalho; possibilidade de contribuição para a geração de novos empregos e absorção de mãode-obra; amortecimento dos impactos do desemprego; manutenção de certo nível de atividade econômica; contribuição para a descentralização de atividades econômicas; potencial para a geração de tecnologias e inovações. Segundo Banco Nacional de Desenvolvimento (BNDES, 2010), o aumento da quantidade de MPE's é um resultado do processo de globalização que estamos passando.

Diante disso, o SEBRAE foi criado com o intuito de apoiar e estimular a competitividade e o desenvolvimento sustentável dos empreendimentos de micro e pequeno porte, em que o lucro não ultrapasse um faturamento bruto anual de até R \$ 3,6 milhões. Essa instituição vem atuando a mais de 40 anos em todo o Brasil, em que além da sede nacional, existem nas 27 unidades da federação, ofertando cursos, seminários, eventos, feiras, palestras, consultorias e assistência técnica capazes de estimular e renovar o conhecimento e capacitação de qualquer pequeno negócio em qualquer setor (SEBRAE, 2008).

O SEBRAE atua como mediador para incentivar e valorizar a participação das MPE's, entendidas que representam quase $90 \%$ do mercado brasileiro, e impulsionar o desenvolvimento econômico do país. Diante disso, uma política preferencial elaborada para as MPE's no processo de compras governamentais corresponde ao caminho para a promoção do desenvolvimento local e a qualificação dessas empresas. Desta forma, o SEBRAE atua em busca de que essa política de incentivo seja implementada nas aquisições do setor público (SEBRAE, 2008).

No que diz respeito a participação de MPE's nas compras públicas, Lopes, Andrade e Ferreira (2015) verificaram a inexistência de informações relevantes sobre os procedimentos a serem adotados por parte dos gestores, dificuldade das empresas organizarem os documentos necessários para participar do certame, o receio das MPE's em fornecer para os entes públicos devido ao fato de não possuírem capital de giro considerável para suprir os custos caso ocorra atraso no pagamento e a baixa utilização dos benefícios concedidos pela legislação.

Outros desafios também são enfrentados pelas MPE's, tais como: pouco apoio econômico; ausência de políticas públicas no planejamento de ações e programas de apoio; carga tributária ainda elevada; falta de mão-de-obra qualificada; e pouco conhecimento gerencial (SEBRAE, 2008).

Barros e Mendonça (1997) propõem como saída para as MPE's a formação de redes, cooperativas ou consórcios capazes de permitir que haja a potencialização dos recursos e dos esforços, contribuindo com isso para o fomento da inovação, da busca de novos conhecimentos, do relacionamento entre partes, dos sistemas de gestão, de logística e de comunicação. para que se garanta a saúde financeira das micro e pequenas empresas.

Já no que tange o processo de compras públicas, Lopes, Andrade e Ferreira (2015) vão além, sugerindo a elaboração de projetos que coordenem ações estratégicas, entre elas a criação de parcerias entre o município e os órgãos de classe existente, como exemplo a CDL (Câmara de Dirigentes Lojistas), por possuírem domínio do cenário local e o SEBRAE, por ser um agente articulador de políticas públicas. Tais parcerias serviriam como um canal de
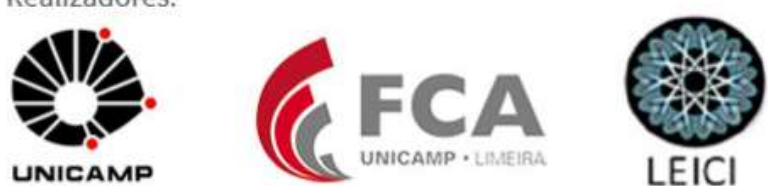
disseminação das informações e de capacitação, a fim de proporcionar um melhor entendimento sobre o tema.

Desta forma fica evidente a participação dos gestores e também o preparo dos mesmos para lidar com essas questões que são inovadoras para a gestão a pública. Nesse caso, temos novamente a contribuição de Lopes, Andrade e Ferreira (2015) que informam a necessidade de os gestores públicos perceberem que são entes primordiais e fundamentais para o sucesso das políticas públicas, levando em consideração o impacto que seu trabalho pode ocasionar no desenvolvimento local e regional, pois se trata de um ciclo, em que ao se utilizar o poder de compra no intuito de fomentar os pequenos negócios da região, faz-se com que o dinheiro fique na mesma localidade, promovendo com isso geração de emprego e renda.

\section{Metodologia}

De acordo com Gil (2008, p. 42) pode-se definir pesquisa como "o processo formal e sistemático de desenvolvimento do método cientifico". Seu objetivo fundamental como estudo de pesquisa é descobrir respostas para problemas mediante o emprego de procedimentos científicos.

Esta pesquisa apresenta um cunho metodológico quali-quantitativo. No que se refere aos fins, esta pesquisa apresenta um caráter descritivo. Para Gil (2008), o método descritivo tem como objetivo principal a descrição das características de uma dada população, possibilitando a observação, a análise e a interpretação do assunto em questão.

Quanto à amostragem, trata-se de não-probabilística. Com relação aos meios de coleta de dados optou-se por estudo de campo, pois este consiste no estudo de um único grupo ou comunidade em termos de sua estrutura social, que, neste caso, são os micros e pequenos empresários de um município de médio porte localizado no Sul de Minas Gerais, devido à facilidade de contato com os atores da pesquisa.

Diante do contexto em que estas empresas se inserem, conforme mencionado anteriormente, e com base no objetivo proposto pelo estudo, utilizou-se um questionário semiaberto, composto por questões abertas e fechadas, a partir do qual foi possível coletar dados sobre as experiências dos micro e pequenos empresários no que tange ao processo de participação ou não em procedimentos de compras públicas nos âmbitos municipal, estadual e federal.

As perguntas propostas no questionário foram baseadas no objetivo do estudo, problema de pesquisa e referencial teórico desenvolvido, contendo dezenove questões fechadas, com opções de resposta e cinco questões abertas. As questões se referem às dificuldades e aos benefícios que os micro e pequenos empresários encontram para participarem dos processos licitatórios, e aos que nunca participaram quais suas aspirações e indagações por nunca participarem dos processos. Foram feitas perguntas para identificar aqueles que já participaram de algum processo licitatório e aqueles que ainda desconhecem o tema. Diante disso, foram feitas perguntas específicas para coletar informações de ambas as partes, em que aqueles que já participaram foram indagados sobre como ocorreu o trâmite, se houve alguma anormalidade ou discrepância e que impactos foram gerados para a empresa caso tenha existido alguma alteração. Por fim, o questionário apresentou perguntas idênticas para ambos os públicos com o intuito de levantar suas considerações no que tange a melhorias

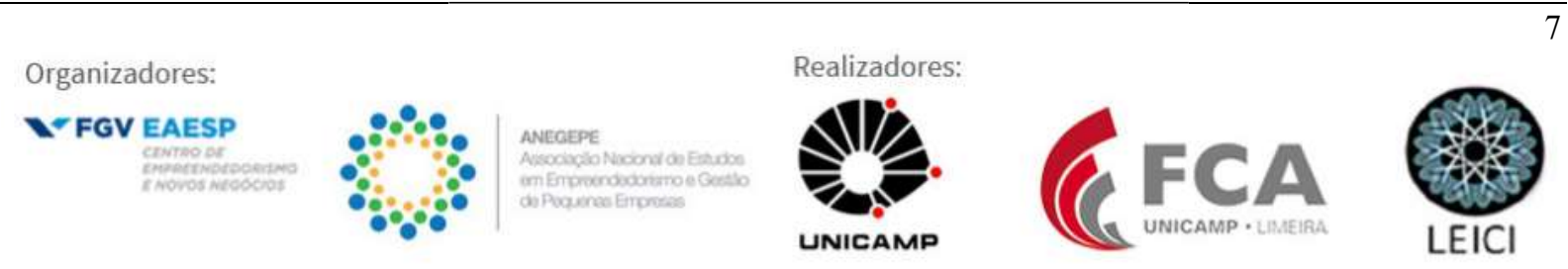


e dificuldades que podem ser encontradas e que soluções podem ser apresentadas e desenvolvidas pelos entes públicos.

Os respondentes foram escolhidos por meio de visitas feitas nos estabelecimentos comerciais que se mostraram aptos e abertos a responderem tal questionário, além de empresários que dispunham de ferramentas de e-mail para o recebimento deste mesmo questionário sob a forma eletrônica. A coleta de dados foi feita durante o período de março a junho do ano de 2017.

O questionário foi aplicado e respondido por 56 empresas, sendo que 20 destas empresas responderam no ato da visita do pesquisador e as outras 36 retornaram via questionário eletrônico. Estes respondentes foram selecionados devido à facilidade do pesquisador em aplicar o questionário, tanto pela forma presencial quanto eletrônica. $\mathrm{O}$ questionário foi enviado via e-mail para aproximadamente 400 empresários, gestores ou colaboradores de MPE's do município pesquisado. Todavia, foram retornados apenas 36 questionários.

Para a análise da pesquisa quantitativa foi utilizada a ferramenta de tabulação online do Google Formulários, que permitiu a criação de planilhas e possibilitou a análise dos dados coletados e sua enumeração.

Assim, para alcançar os objetivos propostos por este trabalho, foram utilizadas a seleção, a simplificação e a síntese dos dados coletados das respostas contidas nos questionários, além dos conceitos apresentados e abordados no referencial teórico.

\section{Resultados e Discussões}

\subsection{Caracterização}

Os primeiros dados que foram analisados por esta pesquisa consistiram na caracterização dos respondentes da pesquisa. Os dados permitiram analisar os perfis dos proprietários, gestores e colaboradores das MPE's de um município de médio porte localizado no Sul de Minas Gerais.

Gráfico 1 - Tempo de empresa (formalizada)

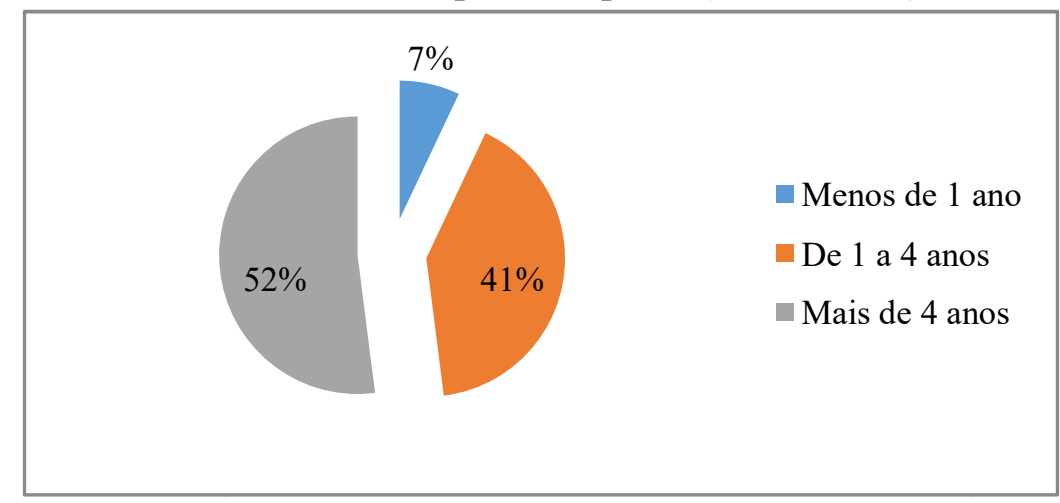

Fonte: Dados da Pesquisa, elaborado pelo autor (2017).

Organizadores:
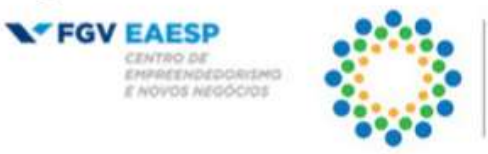

ANEGEPE
Avsociaglo Naciond os Estudion

am Emproconodonamo e Q
de Pogures Erpontas

Realizadores:
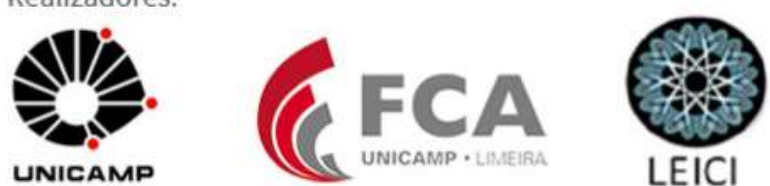
Percebeu-se, conforme Gráfico 1, que mais da metade dos entrevistados pertencem a empresas maduras com no mínimo 4 anos de mercado.

Dentre os respondentes, $48 \%$ se declararam pertencentes ou representantes de empresas do porte de MEI (Microempreendedor Individual), 39\% como ME (Microempresa) e apenas 13\% informaram representar uma EPP (Empresa de Pequeno Porte). Esse resultado denotou que a grande maioria dos indivíduos que responderam à pesquisa pertencem às empresas de porte MEI, demonstrando a importância da mesma no cenário nacional. Segundo estimativas do SEBRAE, existiam cerca de 5 milhões de microempreendedores formalizados no Brasil no ano de 2014 (SEBRAE, 2014b).

Os respondentes puderam declarar seu sexo e sua idade, sendo que $64 \%$ se declararam do sexo masculino e os outros 36\% informaram pertencer ao sexo feminino. Quanto a idade, $28 \%$ informaram ter entre 31 e 36 anos, $25 \%$ disseram ter entre 26 e 30 anos, $16 \%$ com idade entre 43 e 50 anos, $13 \%$ com idade abaixo de 25 anos, $11 \%$ pertencente a faixa etária de 37 a 42 anos e 7\% informaram ter mais de 51 anos.

\subsection{Participação das MPE's em compras públicas}

O segundo momento desta pesquisa buscou conhecer como as empresas e seus representantes obtém ou obtiveram conhecimentos sobre o processo de compras públicas diante dos entes federados e como se deu essa participação.

O primeiro ponto analisado foi a fonte de informação sobre os processos licitatórios nos âmbitos municipal, estadual e federal. No Gráfico 2 é possível constatar como os microempresários tomaram conhecimento dos mesmos.

\section{Gráfico 2 - Fonte de informação sobre processos licitatórios}

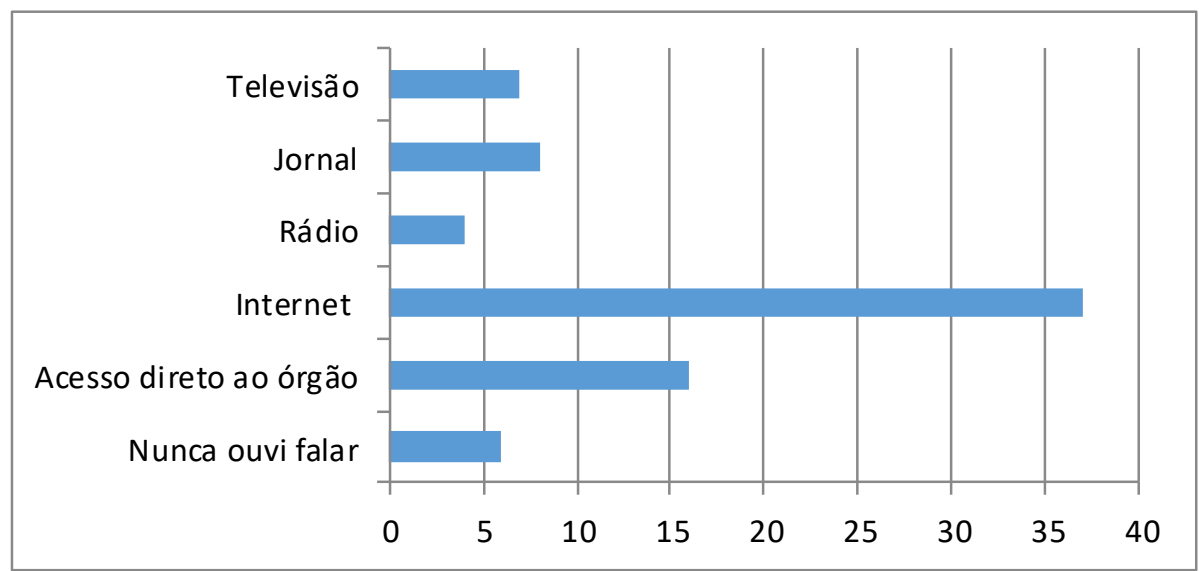

Fonte: Dados da Pesquisa, elaborado pelo autor (2017).

Diante dessa pergunta, pôde-se verificar que a internet tem sido o principal canal de acesso das empresas com relação às informações e consultas de processos licitatórios, seguido pelo acesso do representante da empresa diretamente ao órgão proponente da licitação. Neste momento, podemos perceber que a grande maioria dos entrevistados possui algum tipo de 
canal de informação sobre o tema compras públicas e que uma ínfima parcela ainda desconhece ou não tem tido algum meio de acesso às informações pertinentes aos trâmites.

O Gráfico 3 demonstra o despreparo que se encontram as empresas e seus representantes diante da possível participação em processos licitatórios, pois $36 \%$ dos entrevistados se consideram com nenhuma preparação para participar desses certames.

Gráfico 3 - Grau de preparação para participação em processos licitatórios

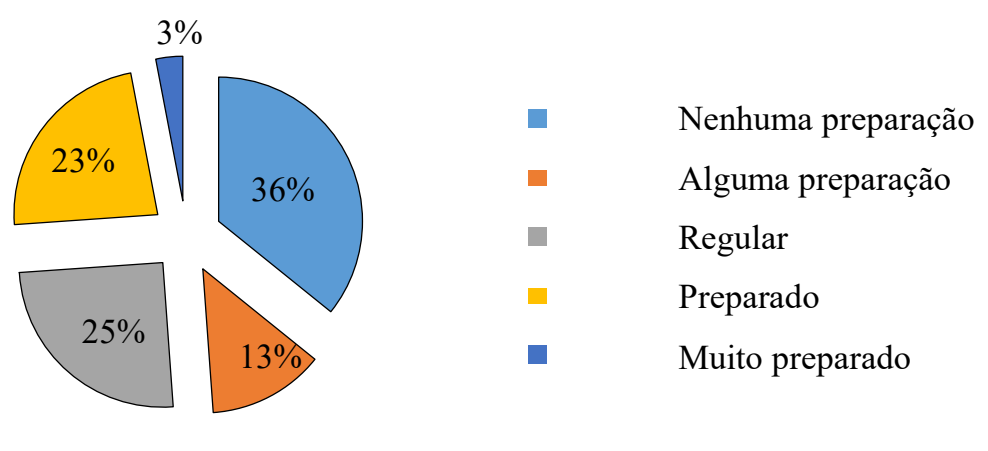

Fonte: Dados da Pesquisa, elaborado pelo autor (2017).

Outra informação importante verificada no Gráfico 3 é que uma pequena parcela de $3 \%$ se diz muito preparada para a participação em processos licitatórios, o que demonstra que 97\% dos respondentes executam suas tarefas sem conhecimento e sem a estrutura necessária. Dessa forma, as empresas e seus representantes têm conseguido acesso às informações sobre os trâmites, porém ainda se consideram despreparados para participar das licitações.

Com relação à participação ou não por parte dos respondentes em processos licitatórios, o retorno obtido foi que apenas um terço, ou seja, 20 respondentes participaram com suas empresas de algum tipo de certame (GRÁFICO 4).

Gráfico 4 - Participação em processos licitatórios

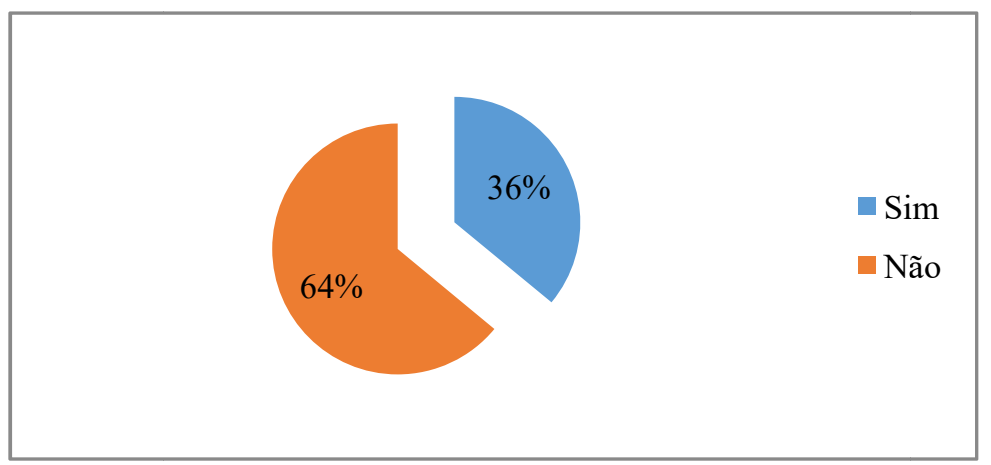

Fonte: Dados da Pesquisa, elaborado pelo autor (2017).

Tomando como base as empresas que já participaram de processos licitatórios, foi constatado que a burocracia e os problemas financeiros enfrentados pelos entes públicos têm sido as principais dificuldades encontradas pelas empresas durante o trâmite licitatório que

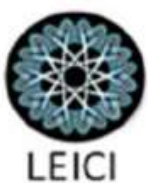


participaram. De acordo com Lopes, Andrade e Ferreira (2015), os entes públicos e seus gestores necessitam perceber a importância das MPE's no cenário que estão inseridas, pois suas ações podem ocasionar desenvolvimento local e regional. Dessa forma, os gestores públicos devem buscar meios para sanar as dificuldades encontradas por essas empresas no que abrange a participação em processos de compras públicas.

Considerando as empresas que já participaram de licitação junto a um ente público, constatou-se que a grande maioria das MPE's realizaram licitações com um ente municipal, conforme Gráfico 5.

Gráfico 5 - Participação dividida por ente federado

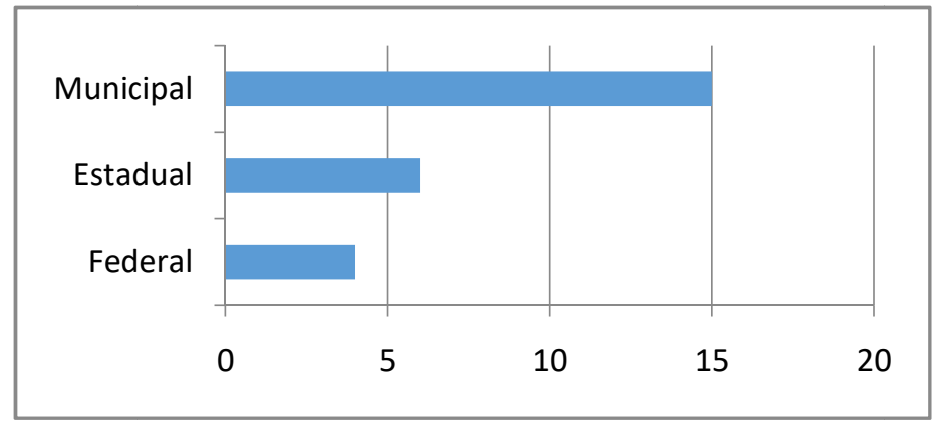

Fonte: Dados da Pesquisa, elaborado pelo autor (2017).

O Gráfico 5 demonstra que um mesmo respondente informou que já participou em processos licitatórios em mais de um ente federado. De acordo com a amostra de 20 empresas que já participantes de algum processo licitatório, apenas 4 declararam que participaram de processos licitatórios em mais de um ente federado simultaneamente.

Considerando o processo licitatório em que participaram, os 20 entrevistados avaliaram a clareza e a organização das informações. Diante desse questionamento, $40 \%$ dos entrevistados declararam que o processo foi regular, sendo que apenas 2 respondentes informaram que o processo foi muito claro e organizado e um respondente apenas declarou que o processo, no qual foi participante, não dispôs de nenhuma clareza antes, durante e depois de seu término.

Por fim, foi abordada a relação de quais ações deveriam ser implementadas e até mesmo melhoradas nos processos licitatórios. Nessa pergunta, os respondentes puderam marcar mais de uma opção. Foram obtidas 50 respostas, sendo que 8 respostas foram marcadas na diminuição dos prazos de pagamento, 10 na diminuição da burocracia, 10 na maior clareza no repasse das informações, 3 na capacitação dos interessados, 2 no provimento de linhas de crédito para os interessados, 9 na provisão de maiores incentivos gerais para empresas da região e 8 na capacitação dos funcionários e dos órgãos públicos com relação aos processos licitatórios.

\subsection{Benefícios e dificuldades encontradas ao participar de compras públicas}


Esse tópico visa relatar as percepções e indagações dos entrevistados, identificando os benefícios e as dificuldades enfrentadas por organizações que participaram ou não de algum processo licitatório e as contribuições obtidas e expostas no referencial teórico deste trabalho.

Inicialmente, foi levantada a questão sobre os impactos da participação das empresas em processos licitatórios. O resultado mostrou que 37,5\% acreditam que a participação pode melhorar as condições da empresa, 33,9\% vislumbram alguma melhora e 28,6\% não verificam nenhuma perspectiva de ganho para sua organização $(28,6 \%)$.

Outro ponto importante levantado foi sobre a percepção dos entrevistados na influência das compras públicas no desenvolvimento local. Nesse ponto, 23 entrevistados responderam que essa ferramenta do ente público é um incentivo importante para que haja desenvolvimento e geração de renda e trabalho no âmbito local. De acordo com Mazzucato (2014), o Estado pode propiciar o desenvolvimento das MPE's e aumentar os níveis de inovação e crescimento econômico e social, por meio do processo compras públicas.

Com isso, os entrevistados puderam elencar o que esse incentivo pode gerar para toda a cadeia produtiva. Verificaram que gera: maiores e melhores relacionamentos das empresas locais com o setor público, facilitando parcerias público-privadas, reduzindo os gastos públicos para promover a aplicação de investimentos em áreas relacionadas ao desenvolvimento local e o bem-estar social; crescimento do mercado local, com o consequente aumento da renda, da geração de novos postos de trabalho e da criação de novas opções de negócios, visando atender o aumento da demanda e aumento da transparência do ente público com a participação do empresariado nesses processos.

O que foi destacado acima pelos respondentes está consonância com o que foi exposto por Souza (1995), para o qual as MPE's oferecem contribuições em diversos campos, como o estimulo à liberdade de iniciativa e capacidade empreendedora, a criação de relações justas entre o capital e o trabalho, a possibilidade de contribuição para a geração de novos empregos e absorção de mão-de-obra local, o amortecimento dos impactos do desemprego que pode ocorrer devido a eventuais crises econômicas, a manutenção da atividade econômica local, a contribuição para a descentralização de atividades econômicas e o potencial campo para a geração de tecnologias e inovações.

Com relação aos benefícios alcançados com a participação em processos de compras públicas, os entrevistados puderam responder a uma questão aberta, elencando algumas vantagens obtidas. Essa questão foi aplicada a todos os entrevistados.

Foram considerados o ganho em escala e a possibilidade de investimento do capital obtido; o aumento do volume de vendas e crescimento da empresa; a possibilidade de aumento da visibilidade da empresa no âmbito regional; a diversificação de clientes; a possibilidade de obter descontos perante o fornecedor, haja vista o aumento da quantidade de compras; a rotação dos estoques, a fim de atualizá-los; o aumento do capital de giro da empresa; a possibilidade de aproximação rápida da empresa a outras empresas e a novos órgãos públicos; a geração de incentivos para a empresa participante e a gratificação do empresário em saber que sua empresa tem total capacidade de participar de um processo de licitação pública.

Sobre a participação ou não em processos licitatórios e sobre eventuais deficiências que tais processos ou até mesmo os entes públicos apresentavam, foram identificadas as seguintes: dificuldade de manter o preço licitado durante certo tempo, diante da grande
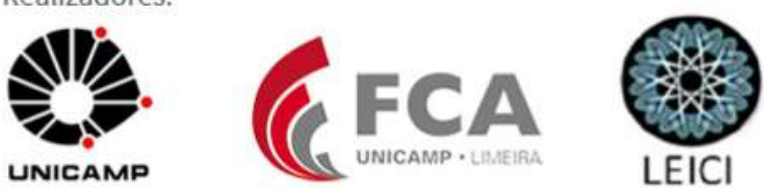
quantidade demandada, gerando prejuízos para as empresas; atrasos na efetivação do pagamento, exigindo um alto capital de giro das empresas para manterem esse espaço de tempo que é necessário aguardar até que haja de fato o pagamento; os processos burocráticos com grandes quantidades de documentos e termos para que a empresa se torne apta a participar do trâmite; a falta de transparência por parte do ente público, que tem gerado favorecimentos e discrepâncias entre os participantes; o descrédito das instituições públicas diante dos recentes casos de desvios de verba e práticas ilícitas dos envolvidos; a falta de diálogo e interação entre empresas e ente público, para que haja a criação de processos rápidos e diretos; a necessidade de tempo e recursos para poder acompanhar os processos de licitação; a ausência de divulgação e repasse de informações necessárias para haver a saudável participação de todos; as constantes mudanças nos processos e as dificuldades de negociação para que haja uma relação de ganhos para ambas as partes.

Lopes, Andrade e Ferreira (2015) entendem que para haver alguma melhoria, tanto pregoeiros quanto a equipe de apoio do município ou região devem ter em mente a necessidade contínua de capacitação, para buscar maiores informações e estudos do cenário em que estão incluídos, buscando novas estratégias de gestão. Matos e Arroio (2011) descrevem que as deficiências recorrentes apresentadas pelas MPE's na participação em processos licitatórios podem estar ligadas também aos recursos humanos escassos e às capacitações técnicas, tecnológicas e gerenciais inexistentes, aliados ao seu menor poderio de barganha perante fornecedores, clientes, bancos e agências de desenvolvimento.

Com relação às melhorias a serem implementadas em novos processos licitatórios, foi proposta uma questão aberta, em que 19 dos 56 respondentes propuseram melhorias na área de divulgação, para que todas as empresas da cidade possam de alguma forma ter acesso às informações relativas à abertura dos processos. Outras respostas contemplaram medidas como: o aumento do acesso à informação quanto nas etapas a serem planejadas para plena participação nestes processos licitatórios; maior clareza para que haja a livre competição e não a criação de práticas tendenciosas; a promoção de capacitação para os envolvidos nos órgãos públicos, evitando consigo problemas técnicos que levam ao aumento da burocracia; a criação de canais seguros para que as empresas possam negociar de forma clara e aberta; a promoção de descrições corretas e amplas dos produtos e serviços a serem solicitados; a diminuição do tempo para pagamento e cumprimento dos prazos para que não haja transtornos para os empresários; a criação de pesquisas de mercado e de cadastramento das empresas interessadas para seguir roteiros rigorosos de cotações a fim de abranger todos os interessados; e a promoção de visitas nas pequenas empresas por parte dos representantes públicos para a criação de laços e o repasse de orientações in loco.

Corroborando com os nossos achados, Lopes, Andrade e Ferreira (2015) frisam a necessidade e a importância da percepção dos gestores públicos para que ações relacionadas ao processo de compras públicas possam ser saudáveis para ambas as partes, fomentando o desenvolvimento e o crescimento local. Para isso, é extremamente necessário que vereadores, prefeitos, assessores e envolvidos na elaboração de processos de compras públicas vivenciem o dia-a-dia das empresas a fim de promover ações em prol de tal objetivo.

\section{Considerações Finais}


O presente trabalho teve como objetivo geral analisar a participação das MPE's de um município de médio porte localizado no Sul de Minas Gerais perante aos processos licitatórios, além de concomitantemente, levantar as opiniões dos representantes das empresas perante os processos de compras públicas, diagnosticar soluções para gargalos diante do ponto de vista destes representantes além de verificar o conhecimento dos empresários entrevistados sobre os benefícios da LC 123/06 (BRASIL, 2006) e de sua nova redação, a LC 147/14 (BRASIL, 2014).

Percebe-se que a legislação não tem sido suficiente para garantir os benefícios e a participação das MPE's nos processos licitatórios. É de responsabilidade dos gestores públicos a aplicação dos benefícios nos editais, porém também é competência destes, promover sua imersão no mercado regional, com o intuito de diagnosticar as principais dificuldades dos microempresários em participarem dos trâmites públicos. Também é responsabilidade dos gestores públicos e dos colaboradores responsáveis pelo andamento dos processos licitatórios a busca por capacitações e treinamentos para qualificação da equipe, que gerará a aplicação efetiva da lei e possibilitará o almejado desenvolvimento e crescimento local.

Diante dos dados coletados, percebeu-se que grande parte dos respondentes se demonstraram interessados em participar de algum processo licitatório, mesmo não tendo capacidade e estrutura necessária para isso. Para a Administração Pública, isso pode ser benéfico, pois em um futuro próximo pode gerar maior competitividade durante as fases de lance, propiciando uma contratação vantajosa para o ente público. Nesse ponto cabem aos gestores buscar mecanismos para ampliar a divulgação dos processos licitatórios com informações claras, para que os micro e pequenos empresários tenham conhecimentos necessários para participarem dos certames com possibilidade de atender às demandas do ente público.

Os empecilhos identificados sobre a participação das MPE's no processos de compras públicas consistem na falta de divulgação dos entes públicos às empresas regionais e a falta de informações sobre os procedimentos a serem realizados, além da desconfiança das MPE's em fornecer para as instituições públicas, devido a casos de atrasos nos pagamentos, que afetam diretamente o capital de giro dessas empresas e aos recentes casos de corrupção governamental que envolvem licitações.

Já com relação aos benefícios apresentados pela participação de MPE's em processos licitatórios, nota-se que essas empresas têm consigo o entendimento de que sua participação tende a gerar bons frutos para o próprio negócio, como: ganho em escala e possibilidade de investimento do capital auferido; o aumento do volume de vendas e crescimento da empresa; possibilidade de aumento da visibilidade da empresa no âmbito regional; a diversificação de clientes e possibilidade de obter descontos perante o fornecedor; a rotação dos estoques, a fim de atualizá-los constantemente; o aumento do capital de giro da empresa, dentre outros. Para que isso ocorra, é sugerida a elaboração de projetos participativos entre o município, as MPE's interessadas e as entidades de classe existentes que apoiam as MPE's, como a Associação Comercial e Industrial do Município e a CDL (Câmara dos Dirigentes Lojistas), além do SEBRAE. Essas parcerias tornaram-se um meio de construção e disseminação de informações, com o intuito de ampliar e melhorar o entendimento de todos os interessados sobre o tema.
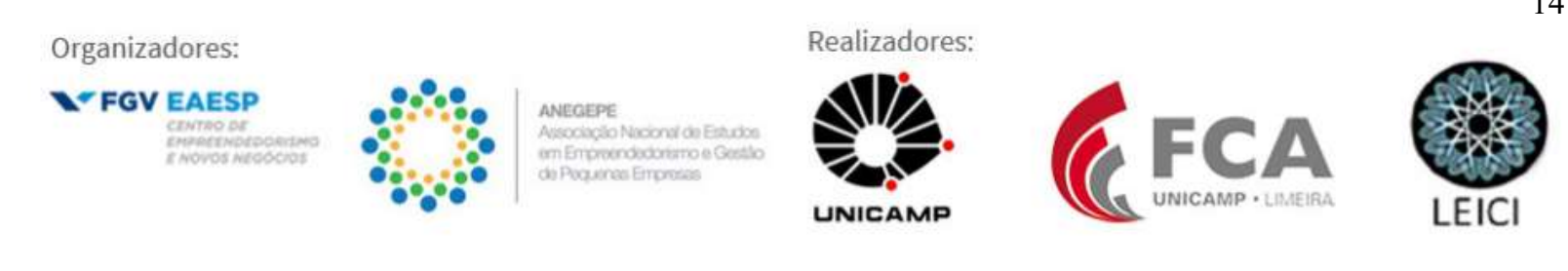
É necessário que os gestores públicos tenham consciência de seu papel inarredável para o sucesso das políticas públicas. Os gestores públicos devem também ter em mente que os processos licitatórios vão além de simples contratações públicas, podendo fomentar os pequenos negócios locais, fazendo com o que o capital fique na região, e promover a geração de emprego e renda. Para essa conscientização, é aceitável que os gestores públicos e os responsáveis pelo andamento dos processos licitatórios se capacitem e estudem cada vez mais sobre o tema, além de identificar as necessidades e os problemas enfrentados pelas MPE's locais para agirem estrategicamente e aplicar todos os benefícios almejados nos processos licitatórios.

Sugere-se, para estudos futuros sobre o tema, uma pesquisa com foco na percepção dos gestores públicos sobre as eventuais dificuldades inerentes à participação das MPE's em processos licitatórios. Outra possibilidade é uma pesquisa sobre os benefícios e as dificuldades enfrentadas por MPE's de outros municípios do mesmo porte, com o intuito de comparar os dados e identificar a percepção dos representantes das MPE's.

\section{Referências}

BANCO NACIONAL DE DESENVOLVIMENTO (BNDES). BNDES lança programa de exportação para micro, pequenas e médias empresas. 2010. Disponível em: $<$ http://www.bndes.gov.br/SiteBNDES/bndes/system/modules/br.gov.bndes.prototipo/templat es/tmp_resultado_busca.jsp $>$. Acesso em: 30 out. 2017.

BARROS, R. P. de; MENDONÇA, R. A absorção de mão de obra no setor de serviços. Revista de Ciências Sociais, Rio de Janeiro, v. 40, n. 1, 1997.

BRASIL. Constituição 1988. Constituição da República Federativa do Brasil de 1988. Brasília, DF: Senado Federal, 1988.

BRASIL. Lei $\mathbf{n}^{\mathbf{0}} \mathbf{8 . 6 6 6}$, de 21 de junho de 1993. Institui normas para licitações e contratos da Administração Pública e dá outras providências. Brasília, DF, 1993.

BRASIL. Lei Complementar $\mathbf{n}^{\mathbf{0}} \mathbf{1 2 3}$, de 14 de dezembro de 2006. Institui o Estatuto Nacional da Microempresa e da Empresa de Pequeno Porte e dá outras providências. Brasília, DF, 2006.

BRASIL. Lei Complementar $\mathbf{n}^{\mathbf{0}}$ 147, de 7 de agosto de 2014. Altera a Lei Complementar no 123, de 14 de dezembro de 2006 e dá outras providências. Brasília, DF, 2014.

BRASIL. Lei $\mathbf{n}^{\mathbf{0}} \mathbf{1 0 . 5 2 0}$, de 17 de julho de 2002. Institui, no âmbito da União, Estados, Distrito Federal e Municípios, nos termos do art. 37, inciso XXI, da Constituição Federal, modalidade de licitação denominada pregão, para aquisição de bens e serviços comuns, e dá outras providências. Brasília, DF, 2002. 
CABRAL, S.; REIS, P. R. da C.; SAMPAIO, A. da H. Determinantes da participação e sucesso das micro e pequenas empresas em compras públicas: uma análise empírica. Revista de Administração, São Paulo, v. 50, n. 4, p. 477-491, out./dez. 2015.

DI PIETRO, Maria Sylvia Zanella. Direito Administrativo. $25^{\circ}$ Edição. São Paulo: Atlas, 2008.

DRUCKER, P. Inovação e espírito empreendedor. São Paulo: Pioneira, 1992. 400 p.

GIL, A. C. Métodos e técnicas de pesquisa social. 6. ed. São Paulo: Atlas, 2008. 218 p.

INSTITUTO BRASILEIRO DE GEOGRAFIA E ESTATÍSTICA (IBGE). As micro e pequenas empresas comerciais e de serviços no Brasil. Disponível em: $<$ http://www.ibge.gov.br/ home/estatistica/economia/microepequenaempresa/default.shtm>. Acesso em: 30 out. 2017.

LOPES, J. V.; ANDRADE, D. M.; FERREIRA, P. A.. Tratamento diferenciado nas contratações públicas: o caso de um município de médio porte localizado no sul de Minas Gerais. In: ENCONTRO DA ASSOCIAÇÃO NACIONAL DOS PROGRAMAS DE PÓSGRADUAÇÃO EM ADMINISTRAÇÃO, 2015, Costa do Sauípe. Anais... Costa do Sauípe, 2015.

MATOS, M. P.; ARROIO, A. Políticas de apoio à micro e pequenas empresas no Brasil: avanços no período recente e perspectivas futuras. Santiago: Nações Unidas, 2011.

MAZZUCATO, M. O Estado empreendedor: desmascarando o mito do setor público vs. setor privado. London: Portfolio-Penguin, 2014. 304 p.

MELlO, C. A. B. de. O conteúdo jurídico do princípio da igualdade. 3. ed. São Paulo: Malheiros, 2011. 48 p.

SEBRAE, Serviço Brasileiro de Apoio a Micro e Pequenas Empresas. Como comprar da micro e pequena empresa. Brasília, DF, 2008. 112 p.

Compras públicas: um bom negócio para sua empresa. Brasília, DF, 2014a. 40 p.

Inovações introduzidas pela Lei Complementar n 147/2014. Brasília, DF, 2014b. $33 \mathrm{p}$.

Micro e pequenas empresas geram 27\% do PIB do Brasil. Brasília, DF, 2014c.

SOUZA, M. C. de A. F. de S. Pequenas e médias empresas na reestruturação industrial. Brasília, DF: Sebrae, 1995. 257 p.

Organizadores:

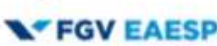

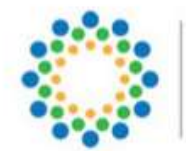

